\title{
Expansion of water chestnut in a small dam reservoir: from pioneering colony to dense floating mat
}

\author{
KRZYSZTOF KUKUŁA \\ ANETA BYLAK* \\ Department of Ecology and Environmental Biology, \\ University of Rzeszow, Zelwerowicza 4, \\ 35-601 Rzeszów, Poland \\ * Correspondence: \\ Aneta Bylak \\ E-mail:abylak@ur.edu.pl
}

Key words: Central Europe, endangered species, Lythraceae, Trapa natans, water reservoir
Received November 22, 2016.

Revised July 04, 2017.

Accepted July 04, 2017.

\section{Abstract}

Background and Purpose: This manuscript reports on the rapid spread of water chestnut in a shallow dam reservoir. The water chestnut is a critically endangered plant in Poland.

Materials and Methods: From 2008 to 2016 during the vegetation season we investigated the distribution of water chestnut in the Rzeszów dam reservoir.

Results: The colony has grown from sparse individual plants which probably appeared around 2005, to a dense floating mat of plants with the total area of over 14 ha today. Recently water chestnut has also appeared in all shallow parts of the reservoir with weak water flow.

Conclusions: Taking into consideration the dynamic expansion of the water chestnut, it can be assumed that in the near future this species may control many parts of the Rzeszów reservoir, while in others it can be displaced by reeds. It is highly probable then that the total area of water chestnut patches will decrease, rather than increase.

\section{INTRODUCTION}

The Rzeszów reservoir $\left(50^{\circ} 00^{\prime} 50^{\prime \prime} \mathrm{N}\right.$; $\left.021^{\circ} 59^{\prime} 59^{\prime \prime} \mathrm{E}\right)$ was created by 1 construction of a dam on the Wisłok river in 1974 for a drinking water reservoir for the City of Rzeszów located within the city. Recreational use of the reservoir was also envisaged. Initially, it was quite large at 68.2 ha holding 1.8 million $\mathrm{m}^{3}$ of water. However, sediments carried by the river accumulated and made the reservoir shallower. Nowadays, the average depth is $-0.6 \mathrm{~m}$, the area $\sim 40$ ha, and the capacity -0.6 million $\mathrm{m}^{3},-35 \%$ of the initial capacity. Numerous islands and a number of shallow branches and bays have been created (1).

The change in the character of the reservoir has led to the creation of a range of habitats for plants and animals not previously found there. The islands and shores of the reservoir are overgrown with willows and reeds (2). Among the open-water plants in the reservoir habitat, the water chestnut (Trapa natans) has recently appeared, with first information on this species in 2007 (1).

The water chestnut (family Lythraceae) is native to the warm temperate zones of Eurasia and Africa. It is also found in North America, but is an alien species there $(3,4)$. In Poland, water chestnut were once found widely, but nowadays are very rare and critically endangered. At present, only a very few colonies of the water chestnut can be found in southern Poland $(5,6)$. The water chestnut is an aquatic annual plant. It anchors to the bed of the reservoir using the roots and shell of the nut from which 


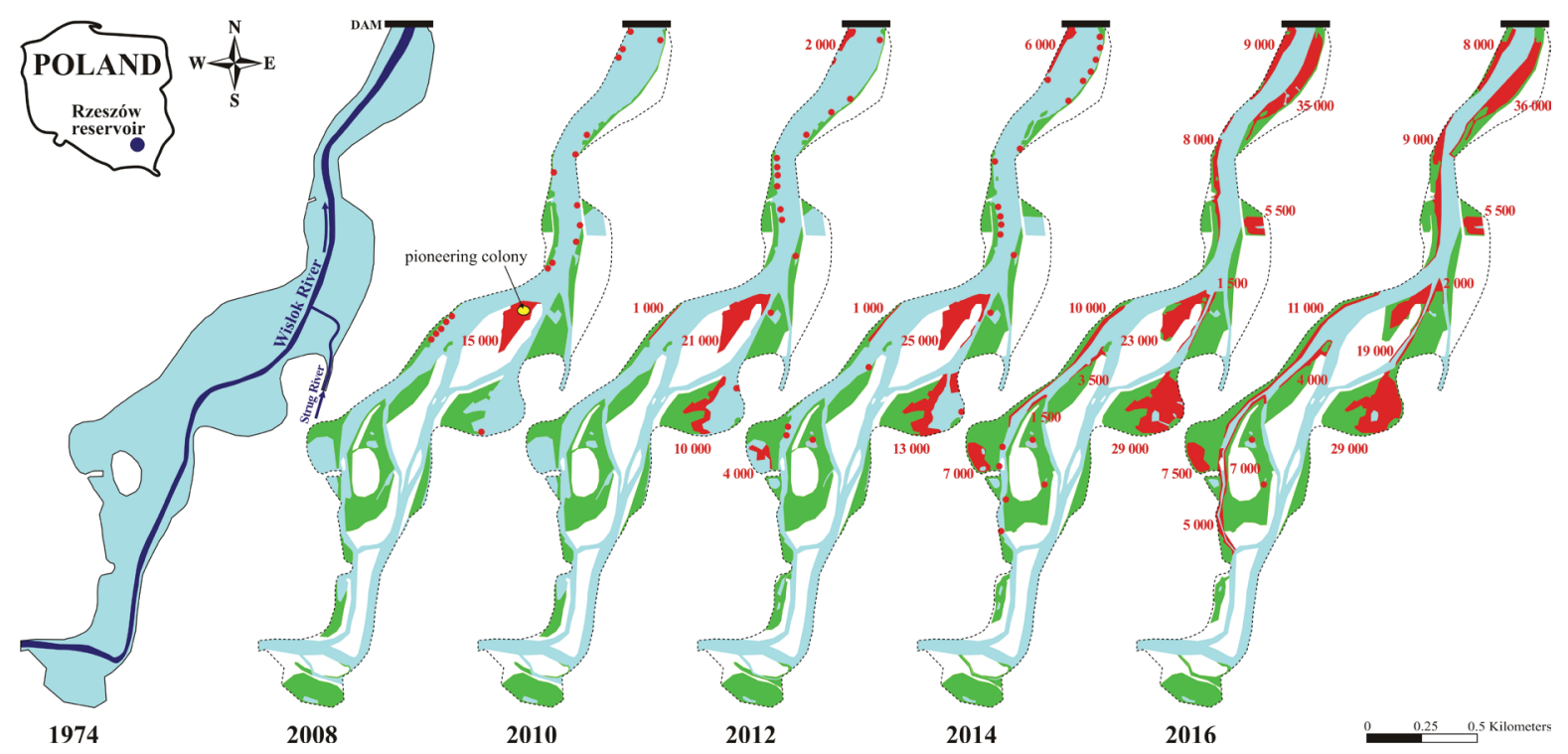

Figure 1. Maps of the distribution of water chestnut patches, the background showing the original extent of the Rzeszów reservoir. shore wetland vegetation - willows andlor reeds (green polygons); water chestnut patches: $>1000 \mathrm{~m}^{2}$ (red polygons), $<1000 \mathrm{~m}^{2}$ (red circles), the area occupied in 2007 (yellow ellipse).

it sprouts. On top of the stem, which is $1.5 \mathrm{~m}$ long, there is a rosette of leathery floating leaves. The rosette reaches a diameter of up to $30 \mathrm{~cm}$ (4). In Poland the water chestnut blooms from May to July (7). The fruits of the water chestnut are formed under water. These are large edible nuts reaching $2-4 \mathrm{~cm}$ in width. The ripe fruits are released following decomposition of the pedicles, and sink rapidly to the bottom where they overwinter in the sediments (8). The optimal habitats for this thermophilous plant are eutrophic reservoirs with neutral or slightly alkaline water $\mathrm{pH}$, and which are $120 \mathrm{~cm}$ to $200 \mathrm{~cm}$ deep, with a soft muddy bed $(4,6,9)$. We assessed the rate of water chestnut spread and its potential for further expansion in the reservoir. We assumed that only the shallow silted part of Rzeszów reservoir was suitable for the water chestnut, and hypothesized that the expansion of this species can be stopped by a greater depth, a stronger water current or competition from other plant species.

\section{MATERIAL AND METHODS}

From 2008 to 2016 during the vegetation season we investigated the distribution of water chestnut in the Rzeszów dam reservoir. In each year of our study, we analyzed field data and made visual delineation of orthorectified images (using ArcGIS.10). In 2008 the research team first searched across the reservoir waters and edges for water chestnut plants. In the following years, data on the occurrence of water chestnut was updated, based mainly on observations made from the reservoir shoreline (recognizing some landmarks for delineating water chestnut distribution). In 2014 the distribution of water chestnut plants was also evaluated from a boat. During field survey by boat, patches of the water chestnut were localised with the use of a GPS receiver. At the same time, fresh highresolution aerial imagery of the Rzeszów reservoir (www. geoportal.pl) was analyzed to estimate and map the coverage area of water chestnut patches and the extent of silting in the reservoir. The physical-chemical water parameters were measured using water quality meter HQ40D (HachLange, Germany), multiparameter sonde 6600 V2-4 (YSI Incorporated, USA) and LF300 photometer (Slandi, Poland).

\section{RESULTS}

The first individual plants probably arrived in the Rzeszów reservoir in 2005. In 2007 there was only one patch of water chestnut of $-1000 \mathrm{~m}^{2}$ in area in the central part of the reservoir. In the survey by boat in 2008 we additionally found single rosettes and small groups in different parts of the reservoir, with a total area of $-1.7 \mathrm{ha}$. In 2010 there were 4 large patches of plants with a total area of -4 ha, accounting for $-10 \%$ of the present surface area of the reservoir. In 2012 chestnut covered an area of -5.5 ha. We also recorded over a dozen smaller patches. In 2014, the water chestnut area had increased significantly to a total area of over $14 \mathrm{ha}$, with the plant occupying most of the shallow places in the reservoir. In 2016 the water chestnut occupied $-35 \%$ of the actual surface of Rzeszów dam reservoir (Figure 1). The total area of the patches was over $14 \mathrm{ha}$ (Figure 2). In the part of reservoir closer to the dam, new patches had appeared, and at the same time some patches in the upper and middle parts of the reservoir had 
decreased in area. In the more shallow sections of the reservoir, the water chestnut had been displaced by reeds. In 2011 during the vegetation season, the measured mean concentration of nutrients in the waters was quite large (nitrite $0.1 \mathrm{mg} \mathrm{L}^{-1}$, nitrate $0.04 \mathrm{mg} \mathrm{L}^{-1}$, ammonium ions $0.3 \mathrm{mg} \mathrm{L}^{-1}$, phosphates $0.3 \mathrm{mg} \mathrm{L}^{-1}$ ) and $\mathrm{pH}$ was slightly alkaline. The average water temperature was $17.3^{\circ} \mathrm{C}$, but the water had been intensively warmed during the summer, reaching up to $28^{\circ} \mathrm{C}$ in the surface layers.

\section{DISCusSION}

Creation of a dam reservoir on a river is usually accompanied by the appearance of new species of plants suiting the new habitats that have formed. Such a situation happened, for example, in the reservoir on the Danube river within the territory of Slovakia. There, among others, the water chestnut appeared because it had found a favorable habitat in the system of muddy branches and oxbow lakes (10). We were unable to determine where the T. natans in Rzeszów reservoir had originated from. A pioneering colony was clearly visible in the central part of the reservoir in 2007. Piórecki (11) mentioned two nearby stands of water chestnut, which later disappeared in the mid-20th century, in the towns of Brzóza Stadnicka and Dąbrówki in the Wisłok valley, $-30 \mathrm{~km}$ from the Rzeszów reservoir. It is possible that the water chestnut populations were preserved somewhere in the Wisłok river valley, and could have been the source from which the species has spread. However, we have not been able to confirm any information about attempts at introducing the species, transfer of water chestnut seeds by human seeming more probable (1). In the Rzeszów reservoir, the water chestnut mostly grows in places where a lot of muddy sediments have accumulated, mainly in the central and lower parts of the reservoir. The physiochemical parameters of the water in the Rzeszów reservoir appear to be favorable to the water chestnut (Figure 1). Similar values of physicochemical parameters of waters were reported from research conducted between 2009 and 2011 (12).

The water chestnut is characterized by a dynamic population density. Under favorable conditions it becomes an expansive plant, quickly dominating in suitable habitats, suppressing the development of submerged macrophytes through shading by the foliage $(4,9)$. The species appears to be able to develop and maintain a population of extremely high density (13). One stem can form many branches, each ending in a rosette of floating leaves. One rosette usually produces from 10 to 15 or even 20 seeds (14). Rapid early growth in spring each year, from nuts overwintering in the sediments, allows early pre-emption of the water surface (13). In the Rzeszów reservoir in 2010 the total area of rosette floating leaves was about 4.0 ha, while in 2016 the total area of the larger patches increased over three times to 14 ha.

If environmental conditions are favorable to the water chestnut, the rosettes of floating leaves can gradually cover the whole surface of the reservoir (3). The great success of $T$. natans at colonizing and monopolizing an aquatic habitat is also a function of its highly productive clonal growth response to low-density conditions (13). The dense mats create shade, limiting the photosynthesis of submerged plants $(9,14)$. Water below the cover of the rosettes then has less dissolved oxygen, and can often fall below $2.5 \mathrm{mg} \mathrm{L}^{-1}$ (15). Additionally, in each autumn, dead T. natans plants drop to the bottom, supplying a large amount of detritus. This causes faster eutrophication of

area (ha)

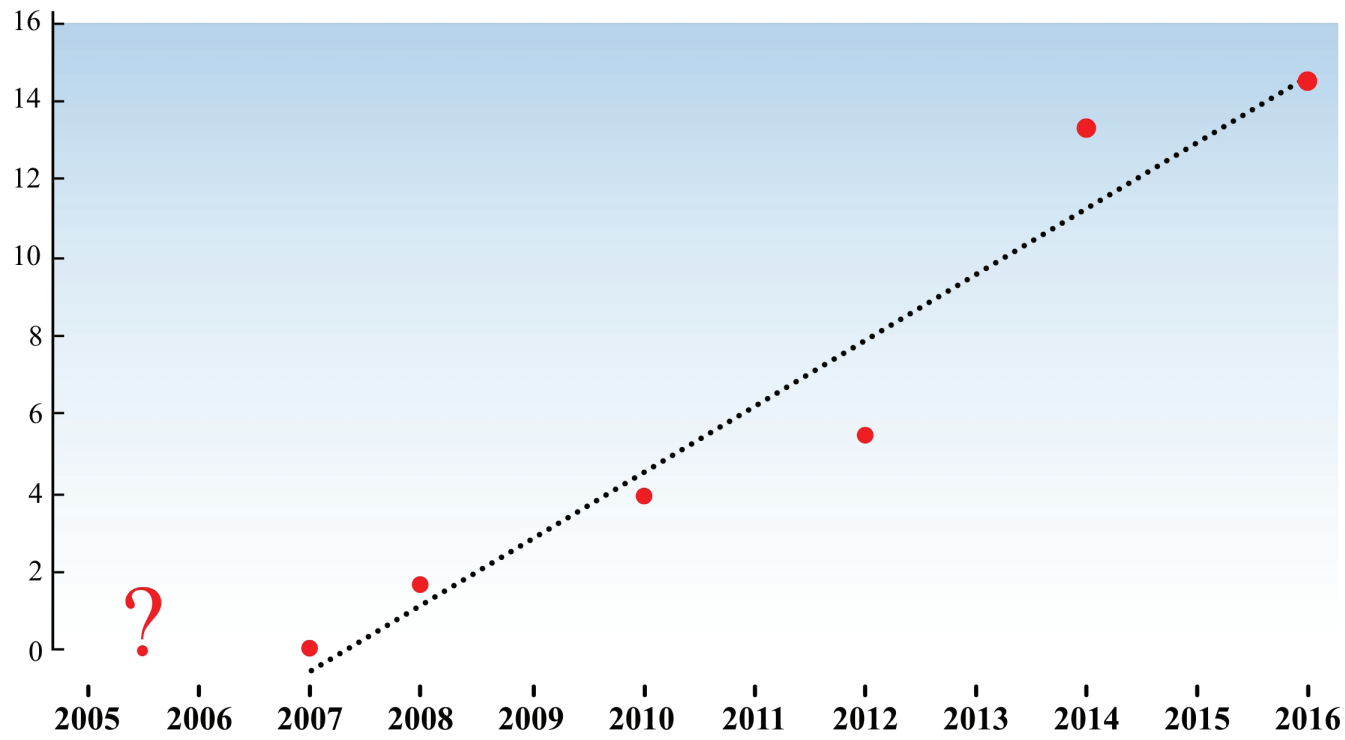

Figure 2. Total area of water chestnut patches in Rzeszów reservoir. 
the reservoir and oxygen is consumed for the decomposition of plant remains $(4,9)$. It can also accelerate further shallowing in the Rzeszów reservoir.

Taking into consideration the dynamic expansion of the water chestnut, it can be assumed that in the near future this species may control many parts of the Rzeszów reservoir, while in others it can be displaced by reeds. Only a few areas with a weak flow of water and shallow depth corresponding to water chestnut requirements remain. Perhaps the current surface area is maximal.

The situation that we have been observing for a decade in this dam reservoir shows that the water chestnut can control a very large area of the water reservoir in a relatively short time. It is also an interesting example of a dam reservoir, which in a natural way was transformed into an ecologically valuable wetland. For this reason, the Rzeszów reservoir is a refuge for many species of marsh and water birds, including endangered species (16), and the patches of water chestnut can be both a feeding ground and a breeding place for them (17). Musk-rats (Ondatra zibethicus) and European beaver (Castor fiber) are also found in this reservoir. Both these species can use the water chestnut as food, and may also contribute to spreading of water chestnut (4). Contrary to natural eutrophic water bodies, the Rzeszów reservoir is disappearing very quickly. Due to the nature of the catchment area (hilly agricultural land), it receives considerable amounts of sediment each year (18). We expect the water level to decrease over the next years and so limit the area of habitat suitable for the water chestnut. It is highly probable then that the total area of water chestnut patches will decrease, rather than increase. Although water chestnut is a threatened species in Poland, it is difficult to propose any recommendations for future management that could lead to its protection, because the main function of the Rzeszów reservoir is related to the drinking water intake.

\section{Acknowledgements}

We thank Stanisław Tabasz, Łukasz Kubejko, and Andrzej Wojton for their help in field work in 2008. We would also specially like to thank Grzegorz Kukuła, and the members of the Polish Anglers Association, for their field assistance and valuable technical support.

\section{REFERENCES}

1. KUKUŁA K, BYLAK A, TABASZ S, KUBEJKO Ł 2013 The largest population of water chestnut Trapa natans in the southeastern Poland. Chr Przyr Ojcz 69: 535-537 (in Polish, English summary)
2. ZIAJA M, WÓJCIK T 2015 Changes in vascular flora of the Rzeszow reservoir after 20 years (SE Poland). Pol J Environ Stud 24: 1845-1854. https://doi.org/10.15244/pjoes/36984

3. CHAMPION PD, CLAYTON JS 2001 Border control for potential aquatic weeds. Stage 2: Weed risk assessment. Science for Conservation, 185, Department of Conservation, Wellington, New Zealand.

4. HUMMEL M, KIVIAT E 2004 Review of world literature on water chestnut with implications for management in North America. J Aquat Plant Manage 42: 17-28

5. MIREK Z, ZARZYCKI K, WOJEWODA W, SZELĄG Z (eds) 2006 Red list of plants and fungi in Poland, Institute of Botany, Pol Acad Sci, Kraków. (in Polish)

6. PIÓRECKI J 2014 Trapa natans L. In: Kaźmierczakowa R., Zarzycki K., Mirek Z. (eds) 2014 Polish red data book of plants. Pteridophytes and flowering plants. PAN, IOP, Kraków, 343-345

7. SZAFER W, KULCZYŃSKI S, PAWŁOWSKI B 1986 Polish plants. Part 1. PWN, Warszawa. (in Polish)

8. SURIYAGODA LDB, SUSUMU A, SUZUKI A 2006 Canopy and fruit with morphological relationship of European and Asian Water chestnut (Trapa spp.). Bull Fac Agr Saga Univ 92: 45-51

9. HABER E 1999 Invasive exotic plants of Canada: fact sheet No. 13, European water chestnut. National Botanical Services, Ottawa, Ontario

10. OŤAHELOVÁ H, VALACHOVIČ M 2002 Effects of the Gabicikovo hydroelectric-station on the aquatic vegetation of the Danube river (Slovakia). Preslia 74: 323-331

11. PIÓRECKI J 1980 Water chestnut (Trapa L.) in Poland. Bibl. Przem. TPN 13: 1-159 (in Polish).

12. GRUCA-ROKOSZ R 2013 Trophic state of the Rzeszów reservoir. JCEEA 30: 279-291. https://doi.org/10.7862/rb.2013.53

13. GROTH AT, LOVETT-DOUST L, LOVETT-DOUST J 1996 Population density and module demography in Trapa natans (Trapaceae), an annual, clonal aquatic macrophyte. Am J Bot 83: 1406-1415. https://doi.org/10.2307/2446095

14. BOLPAGNI R, PIEROBON E, LONGHI D, NIZZOLI D, BARTOLI M, TOMASELLI M, VIAROLI P 2007 Diurnal Exchange of $\mathrm{CO}_{2}$ and $\mathrm{CH}_{4}$ across the water-atmosphere interface in a water chestnut meadow. Aquat Bot 97: 43-48

14. MADSEN JD 1993 Water chestnut seed production and management in Watervliet Reservoir, New York. J Aquat Plant Manage 31: 271-272. https://doi.org/10.1016/j.aquabot.2007.02.002

15. KORNIJÓW R, STRAYER DL, CARACO NF 2010 Macroinvertebrate communities of hypoxic habitats created by an invasive plant (Trapa natans) in the freshwater tidal Hudson River. Fundam Appl Limnol 176: 199-207. https://doi.org/10.1127/18639135/2010/0176-0199

16. KAWA P 2004 Birds of Rzeszow dam reservoir and adjacent areas in the years 1982-2003. Ptaki Podkarpacia 10: 25-52 (in Polish).

17. PALLISSON JM, MARION L 2001 Interaction between coot (Fulica atra) and waterlily (Nymphaea alba) in a lake: the indirect impact of foraging. Aquat Bot 71: 209-216. https://doi.org/10.1016/S0304-3770(01)00182-6

18. KOSZELNIK P, TOMASZEK JA 2002 Loading of the Rzeszów reservoir with biogenic elements - mass balance. Environ. Prot Eng 28: $99-106$ 